
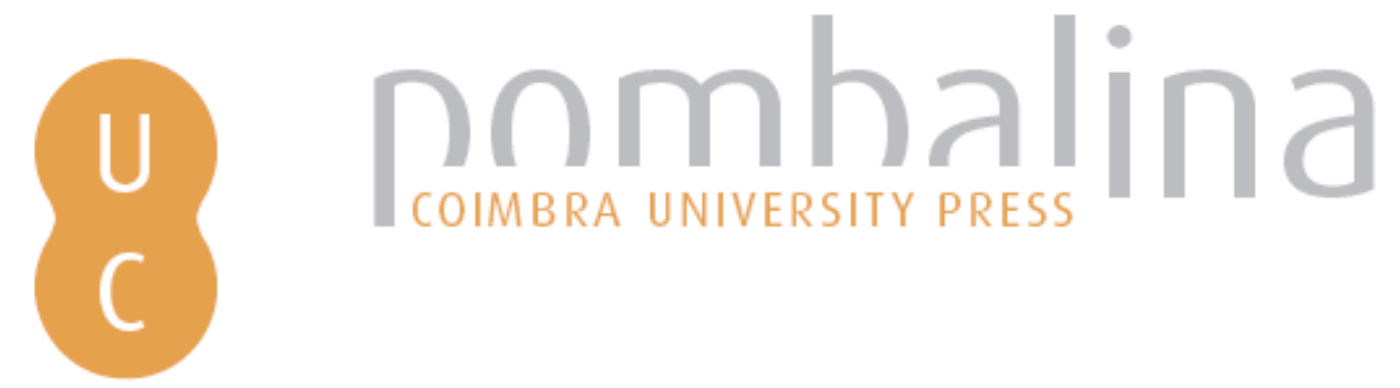

\title{
A alimentação e a Gymnanastica: a saúde e o bem-estar social no discurso higienista no jornal A Província de S. Paulo (1870-1930)
}

\author{
Autor(es): $\quad$ Rocha, Ariza Maria
}

Publicado por: Imprensa da Universidade de Coimbra; Annablume

URL

persistente: URI:http://hdl.handle.net/10316.2/39650

DOI: $\quad$ DOI:https://doi.org/10.14195/978-989-26-1191-4_21

Accessed : $\quad$ 26-Apr-2023 13:40:56

A navegação consulta e descarregamento dos títulos inseridos nas Bibliotecas Digitais UC Digitalis, UC Pombalina e UC Impactum, pressupõem a aceitação plena e sem reservas dos Termos e Condições de Uso destas Bibliotecas Digitais, disponíveis em https://digitalis.uc.pt/pt-pt/termos.

Conforme exposto nos referidos Termos e Condições de Uso, o descarregamento de títulos de acesso restrito requer uma licença válida de autorização devendo o utilizador aceder ao(s) documento(s) a partir de um endereço de IP da instituição detentora da supramencionada licença.

Ao utilizador é apenas permitido o descarregamento para uso pessoal, pelo que o emprego do(s) título(s) descarregado(s) para outro fim, designadamente comercial, carece de autorização do respetivo autor ou editor da obra.

Na medida em que todas as obras da UC Digitalis se encontram protegidas pelo Código do Direito de Autor e Direitos Conexos e demais legislação aplicável, toda a cópia, parcial ou total, deste documento, nos casos em que é legalmente admitida, deverá conter ou fazer-se acompanhar por este aviso.

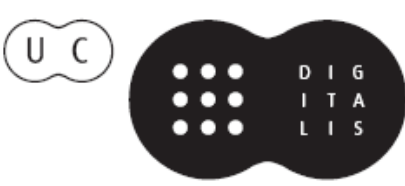




\title{
A alimentação e a Gymnastica: a saúde e o BEM-ESTAR SOCIAL NO DISCURSO HIGIENISTA NO jornal $A$ PRovínCla de $S$. PAUlo (i $870-$ I 930)
}

Food and Gymnastics: health and social welfare in favour of national hygiene in the newspaper The Provincia de S. Paulo (1870-1930)

\author{
Ariza Maria Rocha \\ Universidade Regional do Cariri - URCA \\ Departamento de Educação Física \\ Núcleo de Estudo e Pesquisa em Educação Física - NUPEF
}

Resumo: Esta comunicação, que se limita, temporalmente, ao período que se estende de 1870 a 1930, tem o objetivo de analisar, a partir do jornal A Provincia de S. Paulo, as notícias sobre a questão alimentar atrelada à gymnastica, na busca de propagar uma nova mentalidade no trato do corpo individual e coletivo. Para tanto, recorreu-se à fonte primária, com base no jornal O Estado de São Paulo, atual denominação do periódico. $\mathrm{O}$ acervo possui todas as edições, impressas e on-line, produzidas ao longo dos 140 anos de existência. A leitura do material fornece rastros da vida cotidiana, costumes, práticas sociais e discursos portadores das constantes batalhas partidárias que projetaram, protestaram e idealizaram projetos sociais. Além disso, é importante pensar o jornal como experiência de grupos sociais, devendo, portanto, ser mensageiro de um projeto político, como, por exemplo, o movimento higienista. A par dos documentos, colheram-se informações que permitem compreender os preceitos higienistas na busca do bem-estar, inculcando mudanças de hábitos, comportamentos e normas sobre a saúde, a alimentação, a hygiene e a gymnastica, enfim, sobre o bem-estar do corpo brasileiro.

Palavras-chave: Alimentação. Gymnastica. Saúde. Discursos. Jornal A Província de S. Paulo.

Ав stract: This paper, temporally limited to the decades between 1870 and 1930, aims to analyze the news reported by A Provincia de São Paulo concerning the relation between food and gymnastics in an attempt to spread a new mentality of body care, both individual and collective. Therefore, O Estado de São Paulo, the newspaper's current name, was taken as a primary source for research. The archives contain all editions, printed or online, issued along its 140 years of existence. This reading material provides traces of everyday life, customs, social practices and discourses reporting the constant party battles which projected, protested and idealized social projects. Furthermore, it is important to think of the newspaper as a piece of experience of social groups, as being, therefore, a messenger of a political project, such as the hygiene movement, for example. After analyzing the documents, the information collected permitted the comprehension of the hygienists' precepts in the search of 
well-being proposing changes of habits, patterns of behaviour and rules related to health, food, hygiene and gymnastics, in sum, the well-being of the Brazilian body. Keywords: Food. Gymnastics. Health. Discourses. Newspaper A Provincia de S. Paulo.

\section{INTRODUÇão}

Esta comunicação, que se limita, temporalmente, ao intervalo de tempo que se estende da década de 1870 até à década de 1930, tem o objetivo de analisar, a partir do jornal $A$ Provincia de S. Paulo ${ }^{1}$, as notícias sobre a questão alimentar e a gymnastica ${ }^{2}$ na busca de propagar uma nova mentalidade no trato do corpo individual e coletivo.

A par dos documentos, colhemos informações que permitem compreender os preceitos higienistas na busca do bem-estar, inculcando mudanças de hábitos, comportamentos e normas sobre a saúde, a alimentação, a bygiene e a gymnastica, enfim, sobre o bem-estar do corpo brasileiro.

Para tanto, recorremos à fonte primária, com base no jornal $O$ Estado de S. Paulo, atual denominação do periódico, o qual possui todas as edições já publicadas preservadas, tanto na forma impressa como na digitalizada inclusive com um acervo disponibilizado on-line -, produzidas ao longo dos 140 anos de existência.

A leitura do material fornece rastros da vida cotidiana, costumes, práticas sociais e discursos portadores das constantes batalhas partidárias que projetaram e idealizaram projetos sociais, pelos quais também se realizaram protestos.

Além disso, é importante pensar o periódico como portador de um discurso vinculado aos interesses de uma classe dominante no setor econômico, político e sociocultural, como é o caso do movimento higienista.

Apesar da riqueza do jornal como fonte de conhecimento de um itinerário do passado, é preciso considerar o alerta de Souza e Cabral Filho, os quais argumentam que o jornal é “[...] apenas mais 'um' dos inúmeros discursos possíveis produzidos em determinado momento, pois como qualquer produção humana, está sujeita às subjetividades da época, do autor e de suas intenções”’

${ }^{1}$ A respeito do estudo envolvendo alimentação e publicidade, consultar Braga (2006). Já sobre “Medicina, Higiene e Cosmética na Publicidade do Jornal Badaladas: 1948-1958”, consultar Braga (2012).

${ }^{2}$ Esclareço que a ortografia de época foi mantida respeitando as fontes primárias. A ginástica foi a primeira forma de sistematização dos exercícios físicos compondo, a educação higiênica do corpo urbano em meados do século XIX e, que está na gênese da Educação Física como disciplina escolar, área de estudo e atuação profissional.

${ }^{3}$ Souza \& Cabral Filho 2013: 03. 
Por esse caminho, selecionamos, a partir do acervo, as matérias sobre a temática. Em seguida, adotamos a quantificação e a categorização por décadas. Por fim, recorremos à análise do conteúdo e à organização do material colhido.

No citado recorte histórico, encontramos 165 matérias, entre artigos, documentos oficiais e anúncios, que, ao lado das notícias, tinham como temática a gymnastica e a alimentação. Após uma análise de conteúdo, esse número foi reduzido para 145 objetos jornalísticos. A seguir, apresentamos um excerto do jornal que trata a respeito da temática ora em tela.

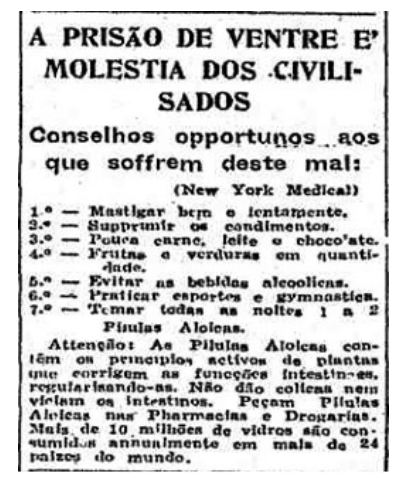

Imagem 1 - Anúncio: "A Prisão de Ventre é moléstia dos Civilisados".

Fonte: O Estado de S. Paulo, 31/03/1938, p. 10.

Como se vê, o reclame associou a imagem médica e estrangeira do New York Medical (College) ${ }^{4}$ para tratar do interesse mercadológico pelo uso de símbolos de unidade e identidade com a autoridade médica, além de recorrer à generalização do uso das pílulas aloicas "em mais de 24 paizes do mundo". Tal anúncio de medicação utilizou-se de conselhos alimentares e da prática de esportes e gymnastica em benefício da saúde, o que, consequentemente, evitaria aquilo que se considerava a "moléstia dos civilizados": a prisão de ventre. Nesse enfoque, o reclame seguia os preceitos higienistas vigentes no citado contexto histórico.

Outras matérias acerca da temática aqui aludida foram encontradas ao longo do referido período histórico, algumas abordando a gymnastica e a alimentação juntas, outras as abordando separadamente, no entanto, tanto uma como outra o faziam sob o viés higienista. Mas, afinal, o que foi esse movimento?

${ }^{4}$ Fundada em 1860, a NYMC tornou-se uma das maiores universidades de ciências da saúde privada dos Estados Unidos da América. Maiores informações em: <http://www.nymc.edu/>. Acesso em: 31 mar. 2015. 


\section{O Movimento higienista no Brasil}

Cuidar da higiene do povo tornou-se uma imperiosa questão social que predominou no Brasil do final do século XIX até meados da centúria seguinte ${ }^{5}$. Cidades como São Paulo tiveram sanitaristas, médicos, arquitetos, educadores e outros defensores que se uniram em torno de práticas e discursos a favor da higienização nacional, desde os espaços públicos aos privados.

Tal movimento, conhecido como higienista ${ }^{6}$, predominou no Brasil na transição da Monarquia à República, condizente com o contexto socioeconômico e político na corrida para tirar o País de seu atraso econômico e cultural. Assim, o projeto de assepsia social passou a constituir uma reforma social e educacional veiculadas em saberes, discursos e práticas, apoiadas pelo olhar do médico no intuito de civilizar, ou seja, limpar o corpo individual e a sociedade, propagar a higiene e prevenir doenças naquilo considerado impuro nos hábitos, práticas e costumes em voga nos mais diversos espaços da cidade e na vida de seus habitantes. Sant'Anna elucida o movimento higienista da seguinte forma:

“[...] Ambição que se expressa de modo exemplar com a promoção da intervenção médica no modo de vida familiar e urbano. Na verdade, numa era de modernização das grandes cidades brasileiras, médicos e engenheiros justificam o devassamento das intimidades familiares e físicas a partir da higiene e da saúde. Como se 'o fantasma puritano da limpeza encontrasse enfim um pretexto científico"'?.

Nesse contexto, multiplicaram-se, rapidamente, as campanhas para o cumprimento da exigência de se livrar de toda a sujeira que pudesse corromper o ser humano e uma série de medidas preventivas destacaram-se como remédio para moralizar a sociedade e combater suas mazelas.

A higiene era a solução para a transformação do corpo, dos espaços e dos costumes dos mais desfavorecidos em prol da manutenção social. Importante salientar que a caçada ocorria diante do corpo sujo do pobre e de seus espaços desfavorecidos, considerados como frutos da ignorância e da falta de moral, e não das condições de vida atreladas a um modelo social emergente de uma cidade industrial. A limpeza do pobre, principalmente, mas não exclusivamente, seria a garantia da eliminação dos ares poluídos de epidemias, causadoras das doenças físicas e dos males morais. Nesse sentido, Vigarello descreve a "ética da pureza" como uma solução pedagógica, pois

\footnotetext{
${ }^{5}$ Para conhecer a história da saúde e da prática médica em Portugal, consultar Braga 2006.

${ }^{6}$ Consultar Góis Júnior 2007.

${ }^{7}$ Sant'Anna 1996: 122.
} 
"[...] esse mecanismo dos tempos futuros não é proposto apenas como um instrumento de saúde, mas também como um instrumento de moral: uma limpeza impondo-se cada vez mais, até atingir os hábitos íntimos dos mais humildes. [...] Não se trata, como no século XVIII, de evocar apenas os vigores, trata-se também de evocar os recursos insuspeitados da ordem. A ética das 'purezas': 'A sujeira nada mais seria do que a insígnia do vício'. E o público alvo, longe de ser a burguesia, é evidentemente o povo pobre das cidades [...]".

O discurso da higienização tomou para si a função de moralizar, institucionalizando a necessidade de inventar, disciplinar, administrar, fiscalizar e punir, segundo as regras de condutas, comportamentos e costumes, a gestação de um novo homem em um novo corpo na escola, na fábrica, em casa e na rua.

Assim, o reformismo social e a busca pelo moderno significaram criar um corpo higienizado, cheio de saúde, livre das ignorâncias para limpar, sanear e despoluir tudo o que impedia o crescimento socioeconômico e político no Brasil. Tal concepção é fruto do pensamento liberalista, no qual, consoante Ghiraldelli Junior, "os liberais não titubeavam em jogar às costas da 'ignorância popular' a culpa pelos problemas sociais"'.

Nesse sentido, o movimento higienista configurava-se como um projeto macrossocial para o Brasil. O saber médico penetrava em todos os âmbitos, desde a intimidade familiar ao ordenamento urbano da cidade. E é nesse quadro que a gymnastica - primeira sistematização de exercícios físicos adotada na escola e na sociedade de uma forma geral - e a alimentação foram invocadas para compor a formação do corpo robusto, saudável e forte da população brasileira. Essas ideias foram estimuladas pelas notas da imprensa escrita, particularmente do jornal A Provincia do Estado de S. Paulo, ao qual, nesse contexto, cabia a função de informar e de instruir, incumbindo aos jornalistas a função de intérpretes das luzes ${ }^{10}$, ou seja, "o jornal se destinava a educar aquelas pessoas que por algum motivo não estavam vinculadas a uma instituição escolar. Elas não se dirigiam à escola, mas o jornal chegava semanalmente às suas casas ou oficinas!" ${ }^{11}$.

$\mathrm{O}$ uso do documento escrito como fonte do passado permite aproximar-se da produção social em variadas dimensões humanas que dialogam no tempo e nos espaços geográficos ${ }^{12}$. Além do mais, como portador de ideias e ideais de pessoas e/ou grupos políticos, o jornal tem o potencial de formar opinião

${ }^{8}$ Vigarello 1996: 212.

${ }^{9}$ Ghiraldelli Júnior 1988: 22.

${ }^{10}$ Capelato 1996.

${ }^{11}$ Mizuta 2011: 04.

${ }^{12}$ Sobre o uso do jornal como fonte histórica, consultar: Kreniski \&Aguiar 2011; Calonga 2012; Dines 2012. 
para determinados posicionamentos sociopolíticos. A esse respeito, Souza e Cabral Filho afirmam:

"É impossível negar que ao longo do desenvolvimento da história, os periódicos, como meios de informação, viram-se impregnados por relações de dependência com pessoas ou instituições de poder, sejam estes de caráter econômico, político ou sociocultural. Dessa maneira, a imprensa acaba muitas vezes funcionando como intermediária na transmissão dos ideais dessas instituições e pessoas, promovendo seu poder na sociedade" ${ }^{13}$.

Com tal direcionamento, a imprensa foi empregada para propagar as ideias vigentes de uma época e de grupos sociais, atuando, portanto, como mensageira de um projeto político. A publicação do movimento higienista nas folhas do jornal $A$ Provincia de $S$. Paulo é um exemplo disso, o qual apresentaremos a seguir.

\section{Trajetória do jornal: inicialmente, $A$ Províncla de S. Paulo para o Estado de S. Paulo (Estadão)}

Criado em 04 de janeiro de 1875, o referido jornal foi construído por um grupo de filiação política republicana inspirado por Manoel Ferraz de Campos Salles e Américo Brasiliense. Após a Proclamação da República, em 1889, o periódico foi intitulado O Estado de S. Paulo e, a partir de 1902, passou a ser propriedade da família Mesquita, cuja conexão política era de cunho liberal, momento marcado pela transição da Primeira República à Revolução de 1930.

Em defesa das ideias republicana, liberal e positivista (de cunho evolucionista), estava o projeto do jornal $A$ Provincia em elevar o desenvolvimento político, econômico e cultural do Brasil. Nesse contexto, embalava-se o sonho de uma elite que ansiava por um ideal liberal modernizante e republicano à formação do novo homem, através da educação higienista com sentimentos nacionalistas.

$\mathrm{Na}$ abertura, o jornal, com uma periodicidade diária, teve uma tiragem de 2.250 exemplares. No período em vigência, a moeda que circulava era o réis (de 1833 a 1942) e o custo de assinatura para a capital era de $14 \$ 000$ anual e $7 \$ 000$ semestral. Já as assinaturas para fora do Estado custavam 18\$000 anual e $9 \$ 000$ semestral. Portanto, como se pode depreender, o âmbito da circulação extrapolava os limites do Estado de São Paulo.

De propriedade de uma associação comanditária, os primeiros redatores foram Américo de Campos, Francisco Rangel Pestana e José Maria Lisboa,

\footnotetext{
${ }^{13}$ Souza \& Cabral Filho 2013: 03.
} 
o administrador. $\mathrm{Na}$ ocasião, a tipografia e o escritório funcionavam na Rua do Palácio, n. ${ }^{\circ} 14$.

Inicialmente, o jornal tinha quatro folhas, que abordavam as "Questões Sociais, Assembléia Geral, Actos Officiaes, Secção Livre, Telegrammas, Noticiário, Editaes e Annuncios" ${ }^{14}$. Entre suas matérias, os redatores aceitavam "informações justas e auctorisadas relativas a serviços públicos e desmandos da administração e governo" ${ }^{15}$.

Ao final da década de 1930, o jornal tinha como diretores o Leo Vaz e Júlio Mesquita (1891-1927) e como redator-chefe, Plínio Barreto. A redação e a administração funcionavam na Rua Boa Vista, n. ${ }^{\circ} 180$ e 186, e as oficinas gráficas, na Rua Barão Duprat, n. ${ }^{\circ} 233$. As assinaturas, então, custavam $160 \$$ anual, $80 \$$ semestral e, para o estrangeiro, custava $250 \$$ mensal. Na semana, o preço custava 400 réis e, aos domingos, 500 réis. Para a publicidade, os preços variavam de acordo com a tabela em vigor da época.

Com o passar dos anos, o periódico cresceu na mesma proporção em que aumentava sua influência na sociedade paulista e, consequentemente, foi ampliado o número de páginas para oito folhas, com a seguinte divisão interna: "Notícias do Mundo, Notícias do Interior, Notas e Informações, Tribunaes, Serviço Militar, Movimento Religioso, Palcos e Circos, Artes e Artistas, Assumptos Agrícolas, Sociedade, Moda, Notícias Diversas, Notícias do Esporte, Anúncios" ${ }^{16}$.

Em relação à temática, quantitativamente, os seguintes recortes foram encontrados:

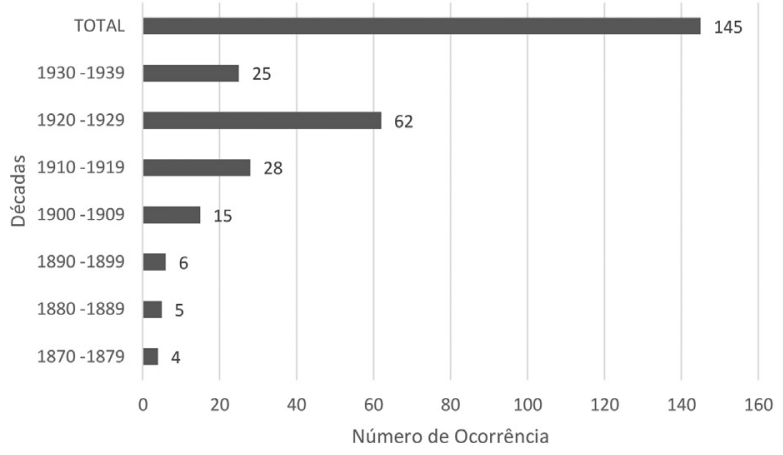

Gráfico 01 - Relação do número de ocorrências de matérias que contemplam a gymnastica e/ou a alimentação entre as décadas de 1870 a 1939

Fonte: Elaborado pela autora (2015).

\footnotetext{
${ }^{14} \mathrm{Na}$ escrita das palavras, respeitamos a grafia da época.

${ }^{15}$ A Província de S. Paulo 1875: Anno 1.

${ }^{16}$ O Estado de S. Paulo 1939.
} 
Como se vê pelo gráfico acima, houve um crescimento na publicação de matérias que envolviam a gymnastica e/ou a alimentação entre as décadas de 1870 e 1939 pelo jornal A Província. É possível observar ainda que, durante a década de 1920, o crescimento foi acima da média. Tal fato ocorreu devido à publicação de um mesmo anúncio 57 vezes pelo médico Dr. Octavio Gonzaga, especialista em moléstias infantis, entre elas, a má nutrição e os seus efeitos sobre o desenvolvimento físico.

Cabe lembrar que, no referido contexto, criança saudável era a criança robusta, conforme ilustra o seguinte recorte do jornal, intitulado "A Robustez e a Alimentação":

"Há regiões salubres do planeta onde a população é mais robusta do que a de outras, sem que se possa atribuir essa diversidade ao clima, á doença ou a salubridade ou inferioridade ás raças. $\mathrm{Na}$ maioria dos casos, tal facto seria exclusivamente por conta da alimentação. Está hoje scientificamente provada a grande influência de certas substâncias alimentares sobre o estado physico dos indivíduos" ${ }^{17}$.

Antenada com as ideias vigentes na Europa, a pauta das discussões do jornal $A$ Província propagou matérias que abordavam a alimentação e a gymnastica de acordo com as concepções higiênicas vigentes, como, por exemplo, segundo a ideia do sociólogo inglês Herbert Spencer ${ }^{18}$, em 1904 ${ }^{19}$, e do Congresso Internacional de Educação Physica ${ }^{20}$, que contou com a participação do primeiro-ministro francês Mr. Poincaré21 o qual se tornaria presidente da França. O Congresso Internacional de Educação Physica foi divulgado a partir dos laços jornalísticos com o Jornal do Commercio, do Rio de Janeiro, no dia 11 de abril de 1913.

Ao propagar o discurso em defesa da assepsia social do brasileiro pela gymnastica e pela alimentação, o jornal retratava o corpo fraco e doente como um inimigo perigoso ou ameaçador e contra o qual a sociedade era convocada a combater. Assim, o mal era visto como "práticas capazes de provocar a deterioração da saúde e da moral, o que 'comprometeria a vida coletiva"”22.

${ }^{17}$ O Estado de S. Paulo 1926: 10.

${ }^{18} \mathrm{O}$ evolucionismo social de Herbert Spencer (1820-1903) chegou à sociedade brasileira nos meados do século XX. O sociólogo britânico escreveu inúmeras obras, entre elas, Educação Intellectual, Moral e Physica (1888), considerada, para alguns, como “a expressão pedagógica máxima” (Spencer 1888: 470).

${ }^{19}$ O Estado de S. Paulo 1904: 01.

${ }^{20}$ O Estado de S. Paulo 1913: 03.

${ }^{21}$ Raymond Poincaré (1860-1934) foi ministro, primeiro-ministro e, em 1913-1920, presidente da nação.

${ }^{22}$ Ghiraldelli Júnior 1988: 17. 
Nesse sentido, é possível acompanhar o esforço do jornal em propagar as ideias higiênicas em defesa da gymnastica e da alimentação, combatendo as práticas do homem sedentário, "dado a uma alimentação succulenta". Como exemplo dessa tentativa, podemos citar o Parecer da Academia de Medicina, publicado no dia 12 de outubro de 1875, apresentado à Assembleia Provincial do Rio de Janeiro. Entre os presentes estavam os seguintes médicos: Dr. Costa Ferraz, Dr. José Pereira Rego Filho, Dr. João Pinto do Rego Cezar e o Dr. João Baptista dos Santos, que foram os relatores do documento. A matéria foi divulgada na íntegra no editorial, intitulada "Questões Sociaes: O ensino da gymnastica nas escolas públicas”. Eis um recorte:

"Todo o exercício gymnastico, activo ou passivo, augmentando a acção peristaltica do estomago e dos intestinos, excita, os vasos chyliferos, assim como a absorpção intersticial, tão necessária ao trabalho de nutrição, favorecendo ao mesmo tempo a energia do apparelho respiratório e a rapidez da absorpção que se effectua na superficie do derma. A gymnastica fecunda ao mesmo tempo todas as fontes do calor animal que se reproduz abundantemente pela frequência da hematose e pelos movimetos continuos dos agentes musculares. Dando firmeza ao tecido dos orgãos animando a vitalidade das funcções assimiladoras, promovendo a nutrição, os exercicios gymnasticos constituem o melhor meio de prevenir as moléstias e de fortificar o organismo. O homem de vida sedentaria e dado a uma alimentação succulenta encontra na gymnastica um meio poderoso de se alliviar da gordura que envolve seus membros e lhes embaraça os movimentos. Galeno fez emagrecer um individuo obeso, obrigando-o a correr todas as manhãs até que o corpo ficasse banhado de abundante suor" ${ }^{23}$.

Da notícia, extrai-se o linguajar científico do médico que justifica a prática de exercícios gymnasticos na educação escolar de meninos e meninas, denominada, até então, de "instrucção pública". Ao se reportar ao passado, o Parecer apoia-se nos fundamentos da medicina do grego Galeno para combater a obesidade, que, segundo o autor, "embaraça os movimentos", ou seja, atrapalha o corpo produtivo do jovem no processo de industrialização da sonhada sociedade moderna brasileira. Nesse contexto, emergem os anúncios de alimentos industrializados antenados com o discurso médico-higienista direcionado à saúde dos escolares, conforme segue a publicidade abaixo:

\footnotetext{
${ }^{23}$ A Província de S. Paulo 1875: 01, grifo nosso.
} 


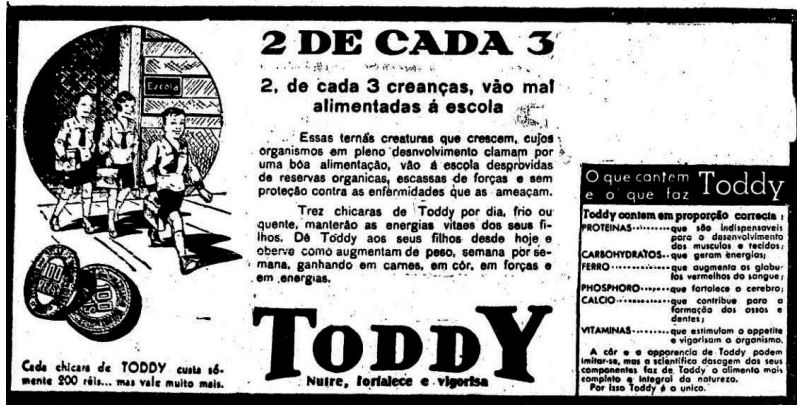

Imagem 02- Anúncio Toddy

Fonte: O Estado de S. Paulo, 10/11/1935, p. 10.

Para além dos muros escolares, os médicos reuniam-se em congressos para debater os efeitos da alimentação em diferentes patologias da Província. Tal preocupação foi externada no convite da "Associação Médica Paulistana", publicado no periódico no dia 17 de julho de $1878^{24}$. O convite pontuava 23 questões que seriam discutidas no próximo encontro médico. Dentre elas, destaca-se o item 15: "Qual a influência que exerce na nosologia da província a alimentação dos seus habitantes?”. ${ }^{25} \mathrm{O}$ chamamento exterioriza a preocupação com a alimentação na vida dos habitantes, como também as consequências que poderiam afetar nas doenças. $\mathrm{O}$ anúncio-convite foi assinado pelo Dr. A. Caetano de Campos, Dr. I. X. de Campos Mesquita, Dr. Nicoláu P. C. Vergueiro, Dr. Guilherme Ellis e Dr. A. Gad. ${ }^{26}$. Acompanhando as matérias, o mesmo convite é publicado no dia seguinte.

Outra matéria interessante que julgamos digna de destaque foi a ocorrência do dia 02 de agosto de 1893, em que a Comissão de Câmaras Municipais e Saúde Pública, na íntegra, divulga o Código Sanitário e o de Reforma do Serviço Sanitário, elaborados pela comissão especial nomeada pelo Congresso Legislativo do Estado de São Paulo. A comissão era formada pelos doutores José Joaquim Torres Cotrim, A. Cazemiro da Rocha, Gustavo de Oliveira Godoy e João Américo Soares Baptista.

Trata-se de uma longa matéria que abordava todos os capítulos do Código Sanitário, a saber ${ }^{27}$ : Capítulo I - Rua e praças públicas; Capítulo II - Das habitações em geral; Capítulo III - Das habitações collectivas; Capítulo IV - Hotéis e Casas de Pensão; Capítulo V - Habitações das classes pobres; Capítulo VI - Das habitações insalubres, Capítulo VII - Fábricas e

\footnotetext{
${ }^{24}$ A Província de S. Paulo 1878: 02-03.

${ }^{25}$ A Província de S. Paulo 1878: 02-03.

${ }^{26}$ Respeitamos a grafia dos nomes dos médicos.

${ }^{27}$ Respeitamos a grafia da época.
} 
officinas; Capítulo VIII - Escolas; Capítulo VIII - Theatros; Capítulo IX Alimentação pública; Capítulo X - Padarias, botequins, restaurantes; Capítulo XI - Açougues; Capítulo XII - Mercados; Capítulo XIII - Matadouros; Capítulo XIV - Abastecimento de água; Capítulo XV - Cocheiras e estábulos; Capítulo XVI - Lavaderias Públicas; Capítulo XVII - Latrinas e Mictórios Públicos; Capítulo XVIII - Exgottos; Capítulo XIX - Hospitaes e maternidades; Capítulo XX - Necrotérios; Capítulo XXI - Accidentes nas ruas; Capítulo XXII - Enterramentos; Capítulo XXIII - Cemitérios; Capítulo XXIV - Precauções immediatas contra moléstias epidêmicas e transmissíveis; Capítulo XXV - Vaccinação e revaccinação.

A publicação na íntegra de cada capítulo tinha o objetivo de informar e educar a higiene da população paulista para que assim pudesse tomar conhecimento e padronizar a conduta, atendendo às diretrizes do Código Sanitário. Entre os itens abordados, estavam os cuidados e as recomendações com a alimentação, debatidos nos capítulos IX, X, XI e XIII, em que as "municipalidades (deverão) exercer a máxima fiscalisação sobre a alimentação pública" ${ }^{28}$ para funcionar com o "extremo asseio" 29 .

Visando à boa execução dos preceitos higiênicos, o Código Sanitário decretava a prática da gymnastica nas escolas, "de accôrdo com o methodo que mais vantagens offerecer" ${ }^{30}$. A prática da gymnastica foi anúncio de instituições escolares, como o Collegio Rosa ${ }^{31}, a$ Escola Normal de São Carlos ${ }^{32}$ e o Instituto Cesario Motta ${ }^{33}$.

Extrapolando os muros escolares, a gymnastica era anunciada nos clubes (Club Gymnastico Portuguez ${ }^{34}$ e C. A. Paulistano ${ }^{35}$ ), nas apresentações artísticas em palcos e circos (Polythema ${ }^{36}$ ), nos ginásios (Gymnasio Paes Leme ${ }^{37}$ ), nos programas de Rádio (Rádio S. Paulo ${ }^{38}$ e Radiotelephonia ${ }^{39}$ ), nos congressos de professores de gymnastica ${ }^{40}$, nos Festivais (Festival da Associação da Imprensa,

\footnotetext{
${ }^{28}$ A Província de S. Paulo 1878: 02.

${ }^{29}$ A Província de S. Paulo 1878: 02.

${ }^{30}$ A Província de S. Paulo 1878: 02.

${ }^{31}$ A Província de S. Paulo 1901: 03.

${ }^{32}$ O Estado de S. Paulo 1916: 03.

${ }^{33}$ O Estado de S. Paulo 1919: 08.

${ }^{34}$ A Província de S. Paulo 1888: 02; 1893: 02.

${ }^{35}$ O Estado de S. Paulo 1933: 08.

${ }^{36}$ A Província de S. Paulo 1892: 01.

${ }^{37}$ O Estado de S. Paulo 1937: 14.

38 O Estado de S. Paulo 1937: 03.

39 O Estado de S. Paulo 1936: 03.

${ }^{40}$ O Estado de S. Paulo 1909: 06.
} 
com Torneios gymnasticos ${ }^{41}$ ), nos Bailes Infantis ${ }^{42}$ e no movimento do escotismo ${ }^{43}$. Como se vê, a recomendação médica estendia-se a todos, ou seja:

"A gymnastica e todos os exercícios são tão necessários ao homem como a mulher, e, á excepção de Cardan, que por um capricho bizarro da imaginação, attribue a longa duração das arvores á sua immobilidade, todos os médicos, todos os hygienistas aconselharam o movimento como necessário á conservação da saúde" ${ }^{44}$.

O método de ensino que predominava na época era o método sueco, criado por Pehr Henrick Ling (1776-1839), nos meados do século XVIII. No Brasil, "A ginástica sueca, os exercícios físicos, os esportes, concorreram, desde o fim do século XIX, para dar maior vigor aos brasileiros das cidades: sem as vantagens dos banhos de rio, dos passeios a cavalo e da vida ao ar livre, nas fazendas e nos engenhos" ${ }^{45}$. Segue a publicidade da época:

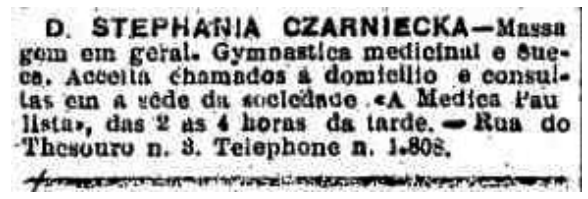

Imagem 03 - Anúncio Gymnatica medicinal e sueca

Fonte: O Estado de S. Paulo, 07/12/1909, p. 07.

A respeito da prática da ginástica e os cuidados com a alimentação dos escolares, os médicos alertavam:

"O horário dos grupos que funcionam em dois periodos traz sérios inconvenientes para o ensino e a saúde da infância. É o que alegam, por sua vez, diversos inspectores escolares no ultimo 'Annuario do Ensino'. A reducção do tempo, de cinco para quatro horas diária, trouxe o sacrificio dos trabalhos manuaes, da gymnastica, dos exercícios militares e dos recreios. A alimentação dos alunos do período da manhan sofre nefasta perturbação, cuja gravidade nenhum hygienista ignora" ${ }^{46}$.

\footnotetext{
${ }^{41}$ O Estado de S. Paulo 1909: 02.

42 O Estado de S. Paulo 1907: 02.

${ }^{43}$ O Estado de S. Paulo 1935: 10.

${ }^{44}$ A Província de S. Paulo 1892: 08.

${ }^{45}$ Freyre 2000: 165.

${ }^{46}$ O Estado de S. Paulo 1914: 05.
} 
Nesse sentido, Olavo Bilac, poeta parnasiano, discursou no jornal a favor da civilidade, urbanidade, racionalidade e disciplina, pois o homem brasileiro conseguiria se destacar através dos seguintes suportes:

“[...] alimentação, instrucção e exercicio e ele se tornara um homem generoso, um homem nobre, um heroe mesmo, quando fôr preciso. Não se diga que no Brasil por não haver uma raça definitiva ou porque soffra a influencia dos maus climas, o contagio do meio elle não seja capaz de grandes surtos" ${ }^{\prime 7}$.

As notícias sobre a alimentação pública em prol da saúde da população ganham destaque e, neste contexto, ganha a visibilidade dos debates veiculados pela imprensa, por exemplo, nas publicações das seguintes matérias: a preocupação do Serviço de Immigração com o fornecimento de alimentos aos imigrantes ${ }^{48}$, de menores sem alimentação ${ }^{49}$, alimentação dos animais ${ }^{50}$, fornecimento de alimentos aos presos pobres ${ }^{51}$, o papel do Comissariado da Alimentação ${ }^{52}$, a alimentação na instruç̧ão publica ${ }^{53}$, nos "Generos alimenticios condemnados" ${ }^{54}$, a enfermidade causada pela má alimentação $0^{55}$, a preocupação com a alimentação natural ${ }^{56}$, anúncios ${ }^{57}$, Inspetoria do Policiamento da Alimentação Pública ${ }^{58}$, o Restaurante Feminino ${ }^{59}$, anúncio do toddy ${ }^{60}$, "Emmagrecer" ${ }^{61}$, reclamação de "alimentação horrível"

Pelo movimento higienista, a temática da alimentação e da gymnastica caminharam em direção à consolidação do conhecimento através dos debates, teses e estudos médicos, cabendo, anos à frente, a consolidação da Educação Física e da Nutrição. Nesse contexto é que se posicionava o "Dia da Raça", conforme ilustração adiante:

\footnotetext{
${ }^{47}$ O Estado de S. Paulo 1916: 05.

${ }^{48}$ A Província de S. Paulo 1889: 01.

${ }^{49}$ A Província de S. Paulo 1897: 04.

${ }^{50}$ O Estado de S. Paulo 1916: 04.

${ }^{51}$ O Estado de S. Paulo 1911: 03.

52 O Estado de S. Paulo 1919: 05.

${ }^{53}$ O Estado de S. Paulo 1910: 02.

${ }^{54}$ O Estado de S. Paulo 1913: 01.

55 O Estado de S. Paulo 1917: 14.

${ }^{56}$ O Estado de S. Paulo 1918: 06.

${ }^{57}$ O Estado de S. Paulo 1934: 14.

${ }^{58}$ O Estado de S. Paulo 1930: 06.

${ }^{59}$ O Estado de S. Paulo 1938: 06.

${ }^{60}$ O Estado de S. Paulo 1935: 10.

${ }^{61}$ O Estado de S. Paulo 1930: 02.

62 O Estado de S. Paulo 1938: 10.
} 


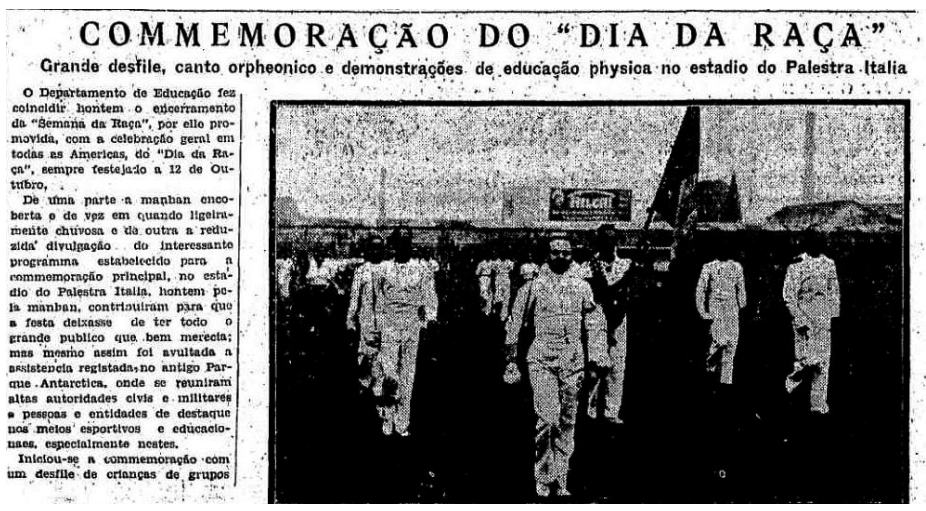

Imagem 04 - Dia da Raça

Fonte: O Estado de S. Paulo, 13/10/1938, p. 06.

Um outro aspecto que não deve ser negligenciado diz respeito ao anseio pela modernidade, influenciado e influenciador das ideias sociais, políticas e educacionais predominantes na época, dentre as quais a do movimento higienista, que concorreu para o predomínio do significado da ginástica e da alimentação como mudança corporal, tendo em vista a formação da higiene do homem moderno.

\section{Conclusão}

O jornal é um importante meio impresso de comunicação diária nos mais diversos aspectos cotidianos (economia, política, arte, moda, etc.) de uma sociedade. Pelas suas publicações, é possível acompanhar a trajetória da produção de documentos escritos e reaproximar-se com o passado e, assim, fazer uma releitura do conhecimento histórico.

A preocupação com a alimentação e com a ginástica, segundo recomendações de médicos, os quais tinham a mídia como porta-voz, não foi apenas uma tendência vinculada ao final do século XIX e início do século XX, pois, com uma nova roupagem em prol da saúde e do bem-estar social, o discurso retoma nos dias atuais, também com a força da mídia, nos programas de alimentação saudável, e com a moda do culto ao corpo, na busca incansável do bem-estar individual e social.

\section{Bibliografia FinAL}

\section{Estudos}

Braga, I. M. R. (2006), "Alimentação e Publicidade Alimentar na Revista ABC (19201926)", Turres Veteres IX: 215-225. Disponível em: <https://www.academia. edu/6581142/>. Acesso em: 20 abr. 2015. 
Braga, I. M. R. (2012), "Medicina, Higiene e Cosmética na Publicidade do Jornal Badaladas: 1948-1958”, Turres Veteras XIV: 57-72. Disponível em: <https:// www.academia.edu/6818343/>. Acesso em: 20 abr. 2015.

Braga, I. M. R. (2001), Assistência, Saúde Pública e Prática Médica em Portugal (séculos $X V$-XIX), Universitária Editora, Lda, Lisboa, Portugal. Disponível em: <https:// www.academia.edu/6581210/>. Acesso em: 20 abr. 2015.

Calonga, M. D. (2012), “O jornal e suas representações: objeto ou fonte da história?” Comunicação E̊ Mercado v.01, n.o 02:79-87.

Capelato, M. H. R. (1986), Os Intérpretes das Luzes: Liberalismo e imprensa paulista. 19201945. Tese de Doutorado em História Social, FFLCH-USP, São Paulo.

Dines, A. (2009), O papel do jornal e a profissão do jornalismo, Summus, São Paulo. <https:// www.gruposummus.com.br/indice/10653.pdf>. Acesso em: 29 abr. 2015.

Freyre, G. (2000), Ordem e Progresso, Record, Rio de Janeiro.

Ghiraldelli Junior, P. (1988), Educação Física Progressiva. A pedagogia crítico-social dos conteúdos e a Educação Física, Loyola, São Paulo.

Góis Junior, E. (2007), "Movimento Higienista e o Processo Civilizador: Apontamentos Metodológicos", in Anais do X Simpósio Internacional Processo Civilizador, Campinas, São Paulo.

Kreniski, G. C. P.; Aguiar, M. do C. A. (2011), O” jornal como fonte histórica: a representação e o imaginário sobre o "vagabundo" na imprensa brasileira (19891991)”, in Anais do XXVI Simpósio Nacional de História - ANPUH, São Paulo.

Mizuta, C. M. M. (2011), Os jornais do século XIX e a pesquisa em história da educação, Faculdade de Artes do Paraná, Curitiba.

Rocha, A. M. (2008), "Educação Física: Diálogos entre Herbert Spencer, Rui Barbosa e Fernando Azevedo" in J. A. B. Bezerra, A. M. Rocha (org.), História da educação: arquivos, documentos, historiografia, narrativas orais e outros rastros, Edições UFC, Fortaleza, 122-134.

Sant'Anna, D. B. de. (1996), "O Receio dos trabalhos perdidos: Corpo e cidade”, Projeto História 13: 121-128.

Souza, D. R.; Cabral Filho, S. (2013), “O Periódico como fonte na pesquisa histórica: trabalho e trabalhadores no Jornal "Diário da Borborema”-Campina GRANDE, 1957-1980”, in XXVII Simpósio Nacional de História. Conhecimento histórico e diálogo social, Natal-RN.

Spencer, H. (1888), Educação Intellectual, moral e physica, Editores Alcino Aranha \& Cia, Portugal, Teixeira \& Irmão: Editores, São Paulo.

Vigarello, G. (1996), O limpo e o sujo: uma história da higiene corporal, Martins Fonte, São Paulo.

\section{Fontes}

Jornal, A Província de S. Paulo (1875-1889) ao Estado de S. Paulo (1889-1930). Acervo. Disponível em: <http://acervo.estadao.com.br/pagina/\#!/1916092613790nac 00049994not/busca/alimenta\%C3\%A7\%C3\%A3o+gymnastic\%C3\%A1 > . Acesso em: 13 fev. 2015. 